\title{
WHEN TWO MEASURES OF DRUG DEPENDENCY DO NOT ACCORD: PREVALENCE, CORRELATES, AND IMPLICATIONS FOR TREATMENT IN THE CRIMINAL JUSTICE CONTEXT
}

\author{
A PREPRINT \\ Jason L. Payne* \\ Centre for Social Research and Methods \\ Australian National University \\ Cameron T. Langfield \\ Centre for Social Research and Methods \\ Australian National University
}

This is the pre-print version of this article. The published article can be found at the following link:

Payne, J. L., \& Langfield C. T. (2021) When two measures of drug dependency do not accord: prevalence, correlates, and implications for treatment in the criminal justice context. Journal of Crime and Justice, 44:1. 131-143. DOI: 10.1080/0735648X.2020.1788973

\footnotetext{
${ }^{*}$ Corresponding author: jason. payne@anu.edu.au
} 


\begin{abstract}
Reducing the volume of drug-related crime has long been a challenge for criminal justice system practitioners and policymakers worldwide. In Australia, this challenge has been tackled using a continuum of early intervention, diversion, and intensive treatment, with drug courts operating as a final alternative to imprisonment for the most serious and frequent drug-dependent offenders. In this study, we explore self-reported dependency and its concordance with the outcomes of a clinical screening tool designed to indicate DSM-V drug dependence in criminal justice populations. We find that not all offenders who self-report their dependency are clinically assessed as dependent. Similarly, not all those who are clinically assessed as dependent identify as such. We also show that these results vary by the frequency, type and longevity of drug use and argue that this discordance has clear implications for the fidelity and success of the drug treatments that are a mandated part of different criminal justice sanctions.
\end{abstract}

\title{
1 Introduction
}

There is now a rich and comprehensive literature on court-supervised intensive drug treatment programs (Bull, 2003; Werb et al., 2015; Vuong, Ritter, Hughes, Shanahan, and Barrett, 2019; Contrino, Nochajski, Farrell, and Logsdon, 2016). This mix of qualitative and quantitative studies mostly concludes that community-based treatment is a viable and cost-effective alternative to imprisonment, however, success is not guaranteed, and there are a number of factors that have the potential to undermine program fidelity and weaken longer-term treatment outcomes. One of these factors concerns the quality of the assessment procedures used to determine suitability for referral (Wood, Miller, and Kaplan, 2017; Logan and Link, 2019) and match offenders to the most appropriate type of treatment. In the criminal justice sector, this type of assessment is complicated. It is both time and resource intensive, uses imperfect instruments, and is undermined by the veil of coercion that exists to encourage offenders into treatment as an alternative to imprisonment. A suspicion long held by drug court practitioners and evaluators alike is that some offenders overstate or embellish their drug use or falsely adopt a drug dependent identity so as to appear more eligible for drug treatment. It is feared that these offenders are the most likely to struggle with drug court programs because they lack the necessary motivation for sustained engagement.

In a study of a more than 14,000 recent drug-using police detainees in Australia it was shown that 53 percent self-identified as drug dependent (Langfield and Payne, 2020). In that paper, the authors noted several problems with the criminal justice system's reliance on self-attribution as a gateway to treatment. To be sure, best practice dictates a preference for validated assessment tools and this remains the gold standard. However, in practice, offenders must volunteer information about their status as drug dependent and consent to treatment prior to referral. For some offenders, there are strong incentives to deny drug use and dependency; for others, there are strong incentivies to overstate or embellish. In this study, we seek to bridge this gap by offering the first ever concordance analysis of self-reported and DSM-V screened dependency collected from police detainees at the point of their arrest and prior to the significant or undue coercive influence of legal or judicial advice. With these data, we estimate the number of drug-dependent offenders (those who were affirmatively screened) who did not self-identify as dependent and consider whether the concordance of these measures varies depending on the type, frequency and longevity of drug use. Although the nature of these cross-sectional data prevents us from carrying out a more complete test of coercion (e.g. testing for a shift in self-reported dependence once legal and judicial advice has been received), we nevertheless provide a critical first step in understanding the baseline concordance of these two measures in a national criminal justice sample.

\subsection{Drugs, crime, and treatment in the criminal justice system}

Our best estimates suggest that between 30 and 50 per cent of recorded crime in Australia is committed in the context of drug use (J. Payne and Gaffney, 2012; Makkai and Payne, 2003). This includes crimes committed by those who are under the influence of drugs, crimes committed in the context of drug acquisition and distribution, and crimes committed to gain money for drug-use lifestyles. Compulsive drug use and drug dependency have long been linked to higher rates of criminal participation and more frequent criminal engagement (Anglin and Speckart, 1986; William H McGlothlin, Anglin, and Wilson, 1977; William H. McGlothlin, Anglin, and Wilson, 1978), while drug treatment appears to significantly reduce intoxicationrelated offending (French and Zarkin, 1992; Rajkumar and French, 1997) and the frequency of income-generating crime (Werb et al., 2015; French and Zarkin, 1992), even if only temporarily (French and Zarkin, 1992). Against this backdrop, criminal justice scholars have long argued that court-supervised drug treatment is an essential part of the wider crime-prevention puzzle.

In Australia, where the data for this study was collected, court-supervised and court-ordered drug treatment programs are a core fixture of the criminal justice system's diversion-to-treatment continuum. As summarised by Wundersitz (2007), this continuum seeks to divert or intervene briefly with low-level drug users and reserves scarce in- and out-patient treatment resources for those offenders with the most severe or entrenched drug-use behaviours. Drug courts-our most expensive and intensive non-custodial programs - are one such example. As 'alternatives to incarceration', Australian drug courts typically require evidence of drug dependency as an essential eligibility criterion (J. Payne and Morgan, 2016). This is partly to ensure 
that the limited intensive drug treatments are targeted at those most in need, but also to ensure that the intensity of the treatment is appropriate.

In practice, criminal justice system drug assessments and triaging systems are imperfect. As a consequence, offenders can be matched to the wrong treatment type or intensity, resulting in no tangible benefit for individual-level drug use or crime (Magura, 2003; Lowenkamp, Holsinger, and Latessa, 2005; Lowenkamp and Latessa, 2004). Worse still, poor service-level triaging can produce adverse consequences, both for individual offenders and whole communities of treatment participants. For drug courts, for example, intervention fidelity can be undermined when one or more offenders are 'over-treated' and when the legitimacy of the treatment relative to the severity of need is questioned (Magura, 2003; Lowenkamp and Latessa, 2004).

The imprecision of offender assessment in this context is further complicated by the coercive nature of the criminal justice setting (Tiger, 2013). Specifically, participation in pre- or post-sentence treatment programs is often predicated as an alternative to more serious or less desirable sanctions. For drug courts, court-supervised treatment is made available as an alternative to an actual or anticipated prison sentence (Logan and Link, 2019; Nolan, 2017). For intermediate court diversion programs, such as the Magistrates Early Referral Into Treatment program ([MERIT], Barnes and Poletti, 2004; Cosden et al., 2006; NSW Department of Health, 2007; Passey, Bolitho, Scantleton, and Flaherty, 2007), drug treatment is suggested as a pathway to a lesser sanction at final sentencing. Although participation is considered 'voluntary' in both cases, the mere fact that an offender agrees to participate in treatment does not indicate their desire or intention to be treated. A more perverse but under-studied consequence of this implicit (or explicit) coercion is that an offender may embellish or lie about their drug dependency to substantiate their treatment eligibility and avoid more serious criminal consequences.

It is here that the present study makes a novel contribution by examining the concordance of self-reported drug dependence and the diagnostic screening outcomes of the UNCOPE, a DSM-V diagnostic assessment of drug dependence that was designed and validated for administration in criminal justice settings (Hoffmann, Hunt, Rhodes, and Riley, 2003; Proctor and Hoffmann, 2016). Specifically, we explore these outcomes for a large sample of police detainees interviewed as part of the Australia Drug Use Monitoring in Australia program (herein referred to as DUMA). By methodological design, these DUMA detainees were interviewed at the point of detention, i.e. following their arrest but before being offered bail or appearing in court. Consequently, their self-report data (both self-reported dependency and their UNCOPE responses) are gathered prior to the potential confounding influence of any implicit or explicit coercive legal or judicial advice. For this reason, these data offer a unique opportunity to estimate how many positively screened drug-dependent offenders do not self-identify as drug dependent and how many offenders see themselves as dependent but do not screen as such on the UNCOPE. To our knowledge, no previous study has documented this discordance in a criminal justice population of this breadth and to this magnitude.

\subsection{Why is this study important?}

The data presented here is important for a number of reasons. First, measuring the intersection between self-reported and clinical dependence provides a unique insight into the criminal justice population for whom court supervised drug treatment is principally targeted. Those who self-report dependence on drugs but who are not clinically indicated as such pose a special challenge for drug treatment providers because although they might benefit from some treatment, they might not qualify or be prioritised if official diagnostic assessments do not indicate immediate need. As research increasingly points to an important relationship between personal identity and behavioural continuity (Dahl, 2015; Leary and Tangney, 2011; McIntosh and McKeganey, 2001), the absence of intervention opportunities for these self-ascribed drug-dependent offenders is likely to be a missed opportunity. Conversely, a reliance on self-reported dependence in a largely inflexible system of treatment intensities and modalities could see these offenders overtreated for a level of drug use that has not yet progressed to a severity defined by the DSM-V.

Second, there are those offenders who are clinically indicated as drug dependent, but who do not self-identify as such. This population poses a different but equally difficult challenge as they appear in need of intensive treatment but are not yet willing or able to acknowledge that need. If encouraged or enforced to undertake treatment as an alternative to more severe criminal justice outcomes, these offenders may be difficult to engage, especially in the longer term. The treatment literature, for example, has long acknowledged the importance of 'success orientation' (DiClemente, Schlundt, and Gemmell, 2004; Prochaska, DiClemente, and John, 1994; Simpson and Joe, 2004; Gregoire and Burke, 2004) and 'readiness to change' (Gannoni and Goldsmid, 2017; Prochaska et al., 1994) as key drivers of positive long-term treatment outcomes. Similarly, the criminological literature has emphasised 'motivation' and 'responsivity' (Contrino et al., 2016; Cosden et al., 2006; J. Payne and Morgan, 2016) as critical components of holistic justice interventions aimed at reducing risk and reoffending. Those offenders who are clinically indicated as drug dependent but who do not self-identify may be among the most susceptible to coercion into lengthy and intensive treatment programs for which they have limited motivation, experience little procedural fairness and validity, and to which they have minimal long term commitment. 
In other contexts (see J. Payne and Wong, 2018), the DUMA program's access to detainees soon after their arrest could be seen as a methodological disadvantage, for this study, however, it was a key strength. Until now, there has been no large-scale quantification of the concordance (and discordance) of self-reported and DSM-V diagnostically indicated drug dependence.

\section{Methodology}

\subsection{Data}

The data for this study were drawn from the Australian Institute of Criminology's DUMA program. DUMA is the world's longest running repeated cross-sectional survey of police detainees at the point of arrest and detention (Makkai, 1999; Patterson, Sullivan, Ticehurst, and Bricknell, 2018; Voce and Sullivan, 2019). Modelled on the US Arrestee Drug Abuse Monitoring program ([ADAM], U.S. Department of Justice, 2002), DUMA combines an interviewer-administered self-report survey with voluntary urinalysis testing for the objective measurement of recent pre-custody drug use. In Australia, DUMA has operated quarterly or biennially since 1999 and receives an average response rate of 70 per cent. We limit our analysis of these data to 23 data collection periods during which the UNCOPE instrument was administered. For this period spanning 2004-2010, 31,750 adult detainees were approached and 22,474 (70.1\%) were interviewed. Our final sample comprises 13,818 detainees who completed the UNCOPE screening tool and who self-reported the use of at least one illicit drug in the 30 days prior to their arrest.

Table 1: Sampling selection outcomes

\begin{tabular}{lcc}
\hline & $\mathrm{N}$ & $\%$ \\
\hline Detainees approached (initial sample) & 31,750 & 100.0 \\
Detainees interviewed & 22,474 & 70.1 \\
Detainees who reported any drug use in the past 30 days & 14,475 & 64.4 \\
Detainees screened on UNCOPE (final sample) & 13,818 & 95.5 \\
\hline Source: Australian Institute of Criminology - Drug Use Monitoring Australia 2004-2010 [computer file]
\end{tabular}

\subsection{Measures}

The two principal measures in this study were self-reported dependency and the six-item UNCOPE scale. Self-reported dependency was measured dichotomously for whether the detainee agreed they were dependent on any one of nine illicit drug types (heroin and morphine, amphetamines, cocaine, cannabis, ecstasy, LSD, benzodiazepines, and inhalants). The question was asked separately for each drug type but combined into a single measure of 'any' self-reported dependency. For the two prescription drugs (benzodiazepines and morphine), self-reported dependency was asked specific to illegal or non-prescription use. Importantly, self-reported dependency was asked prior to the administration of UNCOPE to ensure a minimal risk that respondents were primed to identify as dependent based on earlier questioning about the severity and consequences of their drug use.

UNCOPE is a six-item screening tool designed to indicate probable dependency as per the DSM-V diagnostic criteria for substance use disorders. The scale was first designed and validated for use among arrestees in the US ADAM program (Hoffmann et al., 2003; Proctor and Hoffmann, 2016). It was then later adopted into the Australian DUMA program between 2004 and 2010. Although the tool was never validated against actual clinical outcomes in the Australian context, a recent item response theory analysis explored the composition of the scale and confirmed its internal validity (J. Payne and Wong, 2018).

Consistent with the coding specifications for UNCOPE (Hoffmann et al., 2003; Proctor and Hoffmann, 2016), we operationalised drug dependency as a dichotomous variable that indicates probable dependency if the detainee affirms three or more of the scale's six items. These items are: (U) unintended use of drugs; (N) neglecting responsibilities as a result of drug use; (C) wanting to cut down on drug use; $(\mathrm{O})$ having been the subject of others objections about drug use; (P) being preoccupied with thoughts of drug use; and (E) using drugs to alleviate emotional distress or boredom.

We explore the concordance of these two measures by three components that comprise an individual's drug using career-namely, the type of drug an individual is using, the frequency of their recent drug use, and the longevity of their drug use. To do this, we first identified each detainee's primary drug of use, which for the vast majority of detainees was the drug type that they reported using the most frequently in the 30 days prior to their arrest. In the small number of cases where a detainee reported equal frequencies for the use of two or more drug types, the drug type for which they self-reported dependence was taken as their primary drug.

We then categorised the frequency of each detainee's recent use into three groups: use of between 1 and 8 days in the past 30 (or no more than twice per week); use of between 9 and 15 days (more than twice a week but not quite every second day); and 
16 or more days (every second day or more). Finally, the longevity of the detainee's drug use was measured as the number of years since he or she first began using drugs. The number of years was calculated as the interval between the self-reported age of first drug use and the detainee's current age. This was then categorised into four groups measuring initiation in the last two years, initiation between three and five years ago, initiation between six and 10 years ago, and initiation longer than ten years ago.

Table 2: Descriptive statistics of final sample $(n=13,818)$

\begin{tabular}{lcc}
\hline & $\mathrm{N}$ & $\%$ \\
\hline Demographics & & \\
Aged older than 30 & 5,312 & 38.0 \\
Male & 11,588 & 83.9 \\
Indigenous & 2,483 & 18.0 \\
& & \\
Frequency of recent (primary) drug use & 4,870 & 35.2 \\
1-8 days per month & 1,798 & 13.0 \\
9-15 days per month & 7,150 & 51.7 \\
16 days or more per month & & \\
& & \\
Years since first drug use & 331 & 2.4 \\
$0-2$ years & 1,122 & 8.1 \\
3-5 years & 3,259 & 23.6 \\
6-10 years & 9,095 & 65.9 \\
11 or more years & & \\
& 8,786 & 63.6 \\
Primary drug of use & 2,986 & 21.6 \\
Cannabis & 1,550 & 11.2 \\
Speed or Ecstasy & 153 & 2.5 \\
Heroin or Morphine & 343 & \\
Cocaine & & \\
Other & & \\
\hline Source: Australian Institute of Criminology - Drug Use Monitoring Australia $2004-2010$ [computer file]
\end{tabular}

\subsection{Analytical approach}

We used univariate and bivariate analyses to identify concordance, as well as a series of summary calculations that have particular importance for policy and practice. To consider the difference between the users of different drug types, conditioning on the frequency of drug use in the past 30 days, we used a multinomial logistic regression.

\section{Results}

Of the 13,818 detainees who reported using illicit drugs in the 30 days prior to arrest, 68 per cent were screened as drug dependent by UNCOPE and 52 per cent self-reported being dependent when asked directly (Table 2). If both self-report and UNCOPE are combined, the overall prevalence of dependency was 75 per cent. In other words, three in every four police detainees with a history of recent drug use were likely to be dependent because they identified as dependent or because the UNCOPE screening instrument indicated that they were.

As suspected, there was not absolute concordance between the two measures of dependency. In fact, for one in four detainees $(28 \%)$, the rate of discordance was greater for those who screened positive on UNCOPE (32\%) than it was for those who self-reported their dependency (12\%). To clarify, 32 per cent of those detainees who were identified by UNCOPE as dependent did not self-report. Conversely, of those detainees who self-reported being dependent, only 12 per cent were not identified as dependent by UNCOPE. As an estimate of the total sample, only a small number $(6 \%)$ self-reported their dependency without a positive result on UNCOPE. A much larger group of detainees (22\%) were screened as dependent but did not admit to this when asked.

\subsection{Frequency of recent drug use}

Concordance varies by the frequency of recent drug use. As indicated in the bivariate analysis (Table 3), the agreement rate between self-reported dependency and UNCOPE was highest for those detainees using drugs at least every second day or more 
in the past 30 days. This finding holds in the multivariate model, which simultaneously controls for the type of drug used and longevity of use. For example, using the model coefficients from Table 4, the conditional predicted probabilities of concordance can be compared (see Table 5). This shows that even after accounting for the type of drug used and the length of prior use, those with the highest frequency of recent use (30 days in the past month) had the highest overall rate of concordance (78\%). This compares to just 70 percent of those who had used drugs on 20 days of the past month, and 66 percent of those who had used drugs on 10 days of the past month.

\subsection{Longevity of drug use}

In terms of the longevity of drug use, the results were less clear and demand a more nuanced interpretation. For example, across each of the four groups the prevalence of concordance ranged from between 69 and 73 per cent - not a large difference by our estimation. There was also no clear linear trend with the highest rate of concordance being for both the most recent initiators and the users with the longest history of use (both $73 \%$ respectively). That said, the multivariate model produces a clearer picture once the type of drug and the frequency of recent use are held constant. For example, if as a baseline the self-report concordance rate is calculated among those detainees who were indicated as dependent by UNCOPE, then the concordance rate shows a clear linear trend ranging from 51 per cent among those who only started their drug use very recently, to 67 per cent among those who have been using drugs for more than 10 years. The same linear trend did not emerge when self-reported dependency was the baseline. The only modest exception here was for those who started their drug use very recently. Although this group were less likely to self-identify as dependent overall, when they did, it was less often accompanied with an affirmative outcome on UNCOPE.

\subsection{Primary drug of use}

By drug type, concordance was highest for users of heroin and morphine (87\%) and lowest for users of cocaine (67\%). In fact, for cocaine users who were positively screened as dependent by UNCOPE, more than half (54\%) did not self-identify. In comparison, only 11 per cent of heroin and morphine users who identified as dependent by UNCOPE did not self-report their own dependence. These differences are notable and robust even after controlling for the longevity and frequency of recent use. In the multivariate model (Tables 4 and 5), the concordance of self-report and UNCOPE data was highest for heroin and morphine users. Indeed, it was rare for an opiate user to deny their dependency when UNCOPE indicated so (12\%). It was also rare for opiate users who self-identified as dependent not to be screened as such by UNCOPE (4\%). Conversely, discordance was highest for those whose primary drug was cannabis or cocaine with as many as one in three detainees affirmative on one measure, but not the other. Cocaine users, however, less often denied their dependency when UNCOPE produced a positive result ( $19 \%$ vs. $42 \%$ for cannabis users). 
Table 3: Cross-classification of self-report and UNCOPE (\%)

\begin{tabular}{|c|c|c|c|c|c|c|c|c|}
\hline & \multirow[b]{2}{*}{$\begin{array}{l}\text { Self-report } \\
+\quad \text { UNCOPE } \\
\text { positive }\end{array}$} & \multirow[b]{2}{*}{$\begin{array}{l}\text { Self-report } \\
\text { only }\end{array}$} & \multirow[b]{2}{*}{$\begin{array}{l}\text { UNCOPE } \\
\text { only }\end{array}$} & \multirow[b]{2}{*}{ Neither } & \multicolumn{4}{|c|}{ Summary } \\
\hline & & & & & Concordant & Discordant & $\begin{array}{l}\text { Discordant } \\
\text { (UNCOPE as } \\
\text { base) }\end{array}$ & $\begin{array}{l}\text { Discordant } \\
\text { (Self-report } \\
\text { as base) }\end{array}$ \\
\hline Total sample $(\mathrm{N}=\mathbf{1 3 , 8 1 8})$ & 46.4 & 6.0 & 21.7 & 25.9 & 72.3 & 27.7 & 31.9 & 11.5 \\
\hline \multicolumn{9}{|c|}{ Frequency of recent (primary) drug use } \\
\hline $1-8$ days & 19.3 & 4.3 & 26.7 & 49.7 & 69.0 & 31.0 & 58.0 & 18.1 \\
\hline $9-15$ days & 43.8 & 5.8 & 28.3 & 22.1 & 66.0 & 34.0 & 39.2 & 11.7 \\
\hline 16 days or more & 65.4 & 7.3 & 16.6 & 10.7 & 76.1 & 23.9 & 20.3 & 10.0 \\
\hline \multicolumn{9}{|l|}{ Years since first drug use } \\
\hline $0-2$ years & 15.7 & 4.2 & 23.2 & 56.8 & 72.5 & 27.5 & 59.7 & 21.2 \\
\hline $3-5$ years & 31.5 & 4.7 & 26.3 & 37.4 & 68.9 & 31.1 & 45.6 & 13.1 \\
\hline $6-10$ years & 46.6 & 5.7 & 22.7 & 24.9 & 71.5 & 28.5 & 32.8 & 11.0 \\
\hline $11+$ years & 49.2 & 6.4 & 20.7 & 23.7 & 72.9 & 27.1 & 29.6 & 11.4 \\
\hline \multicolumn{9}{|l|}{ Primary drug of use } \\
\hline Cannabis & 39.7 & 7.3 & 22.1 & 30.8 & 70.6 & 29.4 & 35.7 & 15.6 \\
\hline Speed or Ecstasy & 46.5 & 3.5 & 26.7 & 23.3 & 69.7 & 30.3 & 36.5 & 7.1 \\
\hline Heroin or Morphine & 82.8 & 3.1 & 9.8 & 4.3 & 87.1 & 12.9 & 10.6 & 3.6 \\
\hline Cocaine & 27.5 & 1.3 & 32.0 & 39.2 & 66.7 & 33.3 & 53.8 & 4.5 \\
\hline Other & 58.6 & 9.6 & 17.2 & 14.6 & 73.2 & 26.8 & 22.7 & 14.1 \\
\hline
\end{tabular}

Source: Australian Institute of Criminology - Drug Use Monitoring Australia 2004-2010 [computer file] 
Table 4: Multivariate model of discordance (multinomial logistic regression)

\begin{tabular}{|c|c|c|c|c|c|c|c|}
\hline & \multirow{2}{*}{$\begin{array}{c}\text { Self-report + UNCOPE } \\
\text { (Reference) }\end{array}$} & \multicolumn{2}{|c|}{ Self-report only } & \multicolumn{2}{|c|}{ UNCOPE only } & \multicolumn{2}{|c|}{ Neither } \\
\hline & & $\mathrm{b}$ & s.e. & $\mathrm{b}$ & s.e. & $\mathrm{b}$ & s.e. \\
\hline Frequency of recent (primary) drug use & & -0.03 & 0.00 & -0.07 & 0.00 & -0.12 & 0.00 \\
\hline \multicolumn{8}{|l|}{ Years since first use } \\
\hline 3-5 years (vs. 0-2) & & -0.50 & 0.34 & -0.26 & 0.21 & -0.66 & 0.20 \\
\hline $6-10$ years (vs. $0-2$ ) & & -0.57 & 0.31 & -0.60 & 0.20 & -1.11 & 0.19 \\
\hline $11+$ years (vs. 0-2) & & -0.41 & 0.31 & -0.67 & 0.19 & -1.13 & 0.18 \\
\hline \multicolumn{8}{|l|}{ Primary drug of use } \\
\hline Cannabis (vs. Heroin) & & 1.67 & 0.15 & 1.67 & 0.09 & 2.95 & 0.14 \\
\hline Speed/Ecstasy (vs. Heroin) & & 0.58 & 0.18 & 1.27 & 0.10 & 1.80 & 0.14 \\
\hline Cocaine (vs. Heroin) & & 0.02 & 0.74 & 1.71 & 0.24 & 2.44 & 0.26 \\
\hline Other (vs. Heroin) & & 1.35 & 0.24 & 0.56 & 0.18 & 1.03 & 0.22 \\
\hline Constant & & -2.17 & 0.34 & -0.17 & 0.21 & 0.04 & 0.22 \\
\hline
\end{tabular}

$N=13,807$, Log Likelihood $=-14160.82, X 2(24)=5014.40, p=0.00$, Pseudo $R 2=0.15$

Source: Australian Institute of Criminology - Drug Use Monitoring Australia 2004-2010 [computer file]

\section{Discussion}

When drawing together the findings of this study, it is important to remember that clinical interviews are the gold-standard for the assessment and diagnosis of substance use disorders (Contrino et al., 2016; Paquette, Magidson, Swaminath, and Daughters, 2019) and this study does not conclude otherwise. Indeed, it remains essential that intensive drug treatment programs are supported by comprehensive and evidence-based assessment instruments and to do anything else would undermine treatment fidelity (J. Payne and Morgan, 2016). This notwithstanding, full interview-based clinical assessments are limited, not least because their administration is too time consuming and cost prohibitive to be used on a large scale (Wickersham, Azar, Cannon, Altice, and Springer, 2015; Babor et al., 2007). Therefore, detailed interview-based clinical assessment is often reserved for offender groups who are 'pre-screened' for dependence and who signal an intention or willingness to receive treatment. This process of screening, whether formal or informal, does not typically occur until after an offender has received legal advice or has at least been notified of treatment as an alternative to a potentially more serious sentence or penalty. This means that in terms of criminal justice drug treatment programs, neither screening nor the full clinical interview outcomes that follow can be divorced from the implicit coercive context in which treatment is offered and sought. As argued by other research studies (see Perron and Bright, 2008; Tiger, 2013; Gregoire and Burke, 2004), the coercive context is most likely to result in the wilful underreporting of drug-use for fear of self-incrimnination, or an overstatement or embellishment about the severity of drug use so as to appear more suitable for higher levels of treatment intensity that are offered as alternatives to imprisonment.

It is here that the present study offers new insights. Our data, drawn from the Australian Institute of Criminology's DUMA study, is the only large-sample study that collected both self-reported and clinical screening data (UNCOPE) at the point of arrest. Although neither measure is perfect, their administration at the point of arrest provides a unique opportunity to understand their concordance prior to the likely influence of any legal advice or judicial comments about alternative sanction and sentencing outcomes. Indeed, researchers who have been concerned about the potentially negative consequences of implicit or explicit coercion in court-based drug treatment programs (see Perron and Bright, 2008; Tiger, 2013; Gregoire and Burke, 2004) will be particularly interested in the discordance of these two measures and the implications for interpreting program outcomes.

As indicated by the extant literature, self-report and screening instruments never fully agree, and the present study is no exception. Not all detainees who self-identified as drug dependent were positively screened by UNCOPE and not all detainees who were positively screened as drug dependent acknowledged their dependence, with the latter form of discordance considerably more prevalent than the former. There are many different ways to cut and slice these data, but for the purposes of this paper we focus on their relevance to the application and implementation of drug treatment within the criminal justice system.

First, 52 per cent of recent drug-using detainees self-identified as drug dependent. The majority of these detainees (90\%) were also screened as dependent by UNCOPE. Self-identification is a seemingly strong proxy for clinical dependence and further screening may not be needed for detainees who already acknowledge their dependence. This is important from both a research and practical standpoint, especially when administration time and respondent burden are of key concern. Although small in number, those who do self-identify as dependent in the abcense of an affirmative screening result are an important population 
Table 5: Conditional predicted probability of agreement between self-report and UNCOPE

\begin{tabular}{|c|c|c|c|c|}
\hline & Concordant & Discordant & $\begin{array}{l}\text { Discordant } \\
\text { (UNCOPE as } \\
\text { base) }\end{array}$ & $\begin{array}{l}\text { Discordant } \\
\text { (Self-report } \\
\text { as base) }\end{array}$ \\
\hline \multicolumn{5}{|c|}{ Frequency of recent (primary) drug use } \\
\hline 10 days & 65.7 & 34.3 & 64.5 & 20.0 \\
\hline 20 days & 70.0 & 30.0 & 30.5 & 11.6 \\
\hline 30 days & 77.8 & 22.2 & 17.8 & 8.7 \\
\hline \multicolumn{5}{|l|}{ Years since first use } \\
\hline $0-2$ years & 65.0 & 35.0 & 49.3 & 18.2 \\
\hline 3-5 years & 64.8 & 35.2 & 42.8 & 12.0 \\
\hline $6-10$ years & 68.0 & 32.0 & 34.9 & 11.2 \\
\hline $11+$ years & 68.4 & 31.6 & 33.2 & 13.0 \\
\hline \multicolumn{5}{|l|}{ Primary drug of use } \\
\hline Cannabis & 65.7 & 34.3 & 41.8 & 18.3 \\
\hline Speed or Ecstasy & 69.2 & 30.8 & 32.5 & 7.0 \\
\hline Heroin or morphine & 85.5 & 14.5 & 11.9 & 4.0 \\
\hline Cocaine & 65.4 & 34.6 & 42.6 & 4.1 \\
\hline Other & 73.8 & 26.2 & 19.0 & 13.9 \\
\hline
\end{tabular}

of detainees, either because they are overstating the severity of their drug use or because they continue to identify as dependent even though they have begun to desist and the contemporaneous consequences of their drug use have subsided.

Second, a sizeable proportion (46\%) of detainees who did not self-identify as dependent were later positively screened by UNCOPE. It seems that the absence of self-identification is not an equally robust indicator of the absence of dependence, and for this reason, a reliance on self-report methods alone is insufficient to achieve full coverage of all those who might need treatment. In other words, self-report produces relatively few false positive results but a considerable number of false negatives. To remedy this, perhaps a dual implementation process could be used where respondent and assessor burden is of concern. Such a procedure would prioritise full screening only for those recent drug users who do not initially self-report their own dependence.

For drug treatment and drug court programs, these results confirm another important issue that was foreshadowed in our introduction. Namely, that one in three offenders who screened positive on UNCOPE did not self-report their dependence. These detainees are either wilfully denying their drug use so as to avoid self-incrimination or have yet to internalise a drugdependent identity even though they are already experiencing its negative and affective consequences. Now, while it might be the goal of treatment to better educate these offenders about their drug use, there remains the significant challenge of energising and sustaining treatment motivation for those who do not yet consider themselves dependent. Drug court programs, for example, are intensive and lengthy treatment interventions that can last as long as two years (J. Payne, 2006; J. Payne, 2008; J. Payne, 2005). Convincing or encouraging an offender to participate based on their clinical signs of dependence alone may not always yield positive outcomes unless there are significant programmatic efforts to energise and sustain motivation for treatment and change. This is important for all legally mandated participants (J. Payne and Morgan, 2016), but we think it is especially pertinent to offenders who do not acknowledge their dependence and who may, as a result, see less validity in the need for treatment.

Finally, the concordance between self-report and UNCOPE was stronger among longer-term and higher frequency drug users. This result was not unexpected as the more entrenched the drug user, the more likely that they will experience negative and affective outcomes and internalise these experiences as dependence. What matters here is that at this early juncture in the criminal justice process, discordance brings with it two possible, but unfavourable, outcomes. First, those who do not selfidentify as dependent may be more susceptible to coercion if screening tools indicate otherwise. Second, those who self-identify as dependent but are not screened as such may miss an important opportunity for early intervention. Our data suggest that these two unfavourable outcomes are more likely to occur for those who have only recently started their drug use.

A more surprising result was that even after holding constant the frequency and longevity of drug use, the degree of concordance varied by drug type. Specifically, concordance was strongest for heroin and other opiate users and least strong for cannabis 
and cocaine users. In our view, this differential by drug type speaks to the complex nature of drug dependence as a deeply social (and not just behavioural) construction. Drug types carry with them different social meanings. Heroin has long been recognised as a highly problematic and highly addictive drug type. It is often clinically described as a 'drug of dependence', and the popular portrayal of heroin use tends to be through negative stereotypes and pejorative imagery (Allen and Alberici, 2018 Hughes, Lancaster, and Spicer, 2011). In Australia, heroin has long been conceptualised as the final step on a continuum of drug severity (Teesson et al., 2017), whereas cocaine has long been recognised as a more up-market and white-collar drug (Hser, Huang, Brecht, Li, and Evans, 2008; Wagner and Anthony, 2002) reserved for the most affluent and wealthy of drug users (Shapiro, 2002). Very regular cocaine use (every second day or more) might not be confronted with the same social disapproval as the use of heroin or might cause fewer social consequences because those who use it can legitimately afford their habit. The markets for these drugs are also structured differently (Caulkins et al., 2016), with heroin more likely to be purchased in open-air markets, which carry greater risks and have higher rates of contact with the police (Caulkins et al., 2016).

Whatever the reason, these data suggest that there is complexity to the manifestation of drug dependency, dependency identities, and the structured social realities of the frequent use of different types of drugs. This is an area that warrants future exploration, although what matters here is that we appreciate this complexity and recognise its impact on our ability to reliably and accurately assess offenders for treatment in the criminal justice system.

\section{References}

Allen, C., \& Alberici, A.-M. (2018). Once a Junkie, Always a Junkie: A Narrative Analysis of Cinematic Representations of the Attribution of Criminality and Deviancy to Heroin Users. Preprint. doi:10.20944/preprints201805.0115.v1

Anglin, M. D., \& Speckart, G. (1986). Narcotics use, property crime, and dealing: Structural dynamics across the addiction career. Journal of Quantitative Criminology, 2(4), 355-375. doi:10.1007/bf01064260

Babor, T. F., McRee, B. G., Kassebaum, P. A., Grimaldi, P. L., Ahmed, K., \& Bray, J. (2007). Screening, Brief Intervention, and Referral to Treatment (SBIRT). Substance Abuse, 28(3), 7-30. doi:10.1300/J465v28n03_03

Barnes, L. A., \& Poletti, P. (2004). MERIT, Magistrates Early Referral Into Treatment Program: A Survey of Magistrates. NSW: Judicial Commission of New South Wales.

Bull, M. (2003). Just treatment: a review of international programs for the diversion of drug related offenders from the criminal justice system. Queensland University of Technology.

Caulkins, J. P., Disley, E., Tzvetkova, M., Pardal, M., Shah, H., \& Zhang, X. (2016). Modeling the structure and operation of drug supply chains: The case of cocaine and heroin in Italy and Slovenia. International Journal of Drug Policy, 31, 64-73. doi:https://doi.org/10.1016/j.drugpo.2016.02.003

Contrino, K. M., Nochajski, T., Farrell, M. G., \& Logsdon, E. (2016). Factors of Success: Drug Court Graduate Exit Interviews. American Journal of Criminal Justice, 41(1), 136-150. doi:10.1007/s12103-015-9333-3

Cosden, M., Basch, J. E., Campos, E., Greenwell, A., Barazani, S., \& Walker, S. (2006). Effects of Motivation and Problem Severity on Court-Based Drug Treatment. Crime \& Delinquency, 52(4), 599-618. doi:10.1177/0011128705284287

Dahl, S. L. (2015). Remaining a user while cutting down: The relationship between cannabis use and identity. Drugs: Education, Prevention and Policy, 22(3), 175-184. doi:10.3109/09687637.2014.920765

DiClemente, C. C., Schlundt, D., \& Gemmell, L. (2004). Readiness and stages of change in addiction treatment. The American Journal on Addictions, 13(2), 103-119.

French, M. T., \& Zarkin, G. A. (1992). Effects of drug abuse treatment on legal and illegal earnings. Contemporary Policy Issues, 10(2), 98.

Gannoni, A., \& Goldsmid, S. (2017). Readiness to change drug use and help-seeking intentions of police detainees : findings from the DUMA program. Trends and Issues in Crime and Criminal Justice, (520), 1-17.

Gregoire, T. K., \& Burke, A. C. (2004). The relationship of legal coercion to readiness to change among adults with alcohol and other drug problems. Journal of Substance Abuse Treatment, 26(1), 35-41.

Hoffmann, N. G., Hunt, D. E., Rhodes, W. M., \& Riley, K. J. (2003). UNCOPE: A Brief Substance Dependence Screen for Use with Arrestees. Journal of Drug Issues, 33(1), 29-44. doi:10.1177/002204260303300102

Hser, Y.-I., Huang, D., Brecht, M.-L., Li, L., \& Evans, E. (2008). Contrasting Trajectories of Heroin, Cocaine, and Methamphetamine Use. Journal of Addictive Diseases, 27(3), 13-21.

Hughes, C. E., Lancaster, K., \& Spicer, B. (2011). How do Australian news media depict illicit drug issues? An analysis of print media reporting across and between illicit drugs, 2003-2008. International Journal of Drug Policy, 22(4), 285-291. doi:https://doi.org/10.1016/j.drugpo.2011.05.008

Langfield, C. T., \& Payne, J. L. (2020). What factors predict the self-identification of drug dependency among criminal justice populations? Prevalence, correlates, and implications for the criminal justice system. Preprint. doi:https://doi.org/10. 31235/osf.io/b7cjp

Leary, M. R., \& Tangney, J. P. (2011). Handbook of self and identity. Guilford Press.

Logan, M. W., \& Link, N. W. (2019). Taking Stock of Drug Courts: Do They Work? Victims \& Offenders, 14(3), $283-298$. doi:10.1080/15564886.2019.1595249 
Lowenkamp, C. T., Holsinger, A. M., \& Latessa, E. J. (2005). Are drug courts effective: A meta-analytic review. Journal of Community Corrections, 15(1), 5-11.

Lowenkamp, C. T., \& Latessa, E. J. (2004). Understanding the risk principle: How and why correctional interventions can harm low-risk offenders. Topics in community corrections, 2004, 3-8.

Magura, S. (2003). The Role of Work in Substance Dependency Treatment: A Preliminary Overview. Substance Use \& Misuse, 38(11-13), 1865-1876. doi:10.1081/JA-120024244

Makkai, T. (1999). Drug use monitoring in Australia (DUMA): a brief description. Australian Institute of Criminology.

Makkai, T., \& Payne, J. (2003). Drugs and Crime: A study of incarcerated male offenders. Canberra: Australian Institute of Criminology.

McGlothlin, W. H. [William H.], Anglin, M. D., \& Wilson, B. D. (1978). Narcotic Addiction and Crime. Criminology, 16(3), 293-315. doi:10.1111/j.1745-9125.1978.tb00094.x

McGlothlin, W. H. [William H], Anglin, M. D., \& Wilson, B. (1977). An evaluation of the California civil addict program. National Institute on Drug Abuse Rockville, MD.

McIntosh, J., \& McKeganey, N. (2001). Identity and Recovery from Dependent Drug Use: the addict's perspective. Drugs: Education, Prevention and Policy, 8(1), 47-59. doi:10.1080/09687630124064

Nolan, J. (2017). Drug courts: In theory and in practice. Routledge.

NSW Department of Health. (2007). The Magistrates Early Referral Into Treatment (MERIT) Program: Health outcomes. Government Report. NSW Department of Health Sydney.

Paquette, C. E., Magidson, J. F., Swaminath, S., \& Daughters, S. B. (2019). Substance Use Disorders. In D. L. Segal (Ed.), Diagnostic Interviewing (pp. 325-347). doi:10.1007/978-1-4939-9127-3_13

Passey, M., Bolitho, J., Scantleton, J., \& Flaherty, B. (2007). The Magistrates Early Referral Into Treatment (MERIT) pilot program: court outcomes and recidivism. Australian \& New Zealand Journal of Criminology, 40(2), 199-217.

Patterson, E., Sullivan, T., Ticehurst, A., \& Bricknell, S. (2018). Drug use monitoring in Australia: 2015 and 2016 report on drug use among police detainees. Government Document. Australian Institute of Criminology.

Payne, J. (2005). Final report on the North Queensland drug court. Australian Institute of Criminology Canberra, Australia.

Payne, J. (2006). Specialty courts: current issues and future prospects. Australian Institute of Criminology.

Payne, J. (2008). The Queensland Drug Court: a recidivism study of the first 100 graduates. Australian Institute of Criminology.

Payne, J., \& Gaffney, A. (2012). How much crime is drug or alcohol related? Self-reported attributions of police detainees. Trends and Issues in Crime and Criminal Justice, (439), 1-6.

Payne, J., \& Morgan, A. (2016). Building effective interventions for drug users in the criminal justice system: A review of best practice. Government Document. Queensland Courts.

Payne, J., \& Wong, G. (2018). Measuring drug dependence in police custody: An item response theory and differential item function analysis of UNCOPE in Australia. Drug and Alcohol Review, 37(7), 856-864. doi:10.1111/dar.12854

Perron, B. E., \& Bright, C. L. (2008). The influence of legal coercion on dropout from substance abuse treatment: Results from a national survey. Drug and Alcohol Dependence, 92(1), 123-131. doi:https://doi.org/10.1016/j.drugalcdep.2007.07.011

Prochaska, J. O., DiClemente, C. C., \& John, C. (1994). In Search of How People Change: Applications to Addictive Behaviors. American Psychologist, 47, 1102-1114.

Proctor, S. L., \& Hoffmann, N. G. (2016). The UNCOPE: An effective brief screen for DSM-5 substance use disorders in correctional settings. Psychology of addictive behaviors : Journal of the Society of Psychologists in Addictive Behaviors, 30(5), 613-618. doi:10.1037/adb0000170

Rajkumar, A. S., \& French, M. T. (1997). Drug Abuse, Crime Costs, and the Economic Benefits of Treatment. Journal of Quantitative Criminology, 13(3), 291-323. doi:10.1007/BF02221094

Shapiro, H. (2002). From Chaplin to Charlie-cocaine, Hollywood and the movies. Drugs: Education, Prevention and Policy, $9(2), 133-141$.

Simpson, D. D., \& Joe, G. W. (2004). A longitudinal evaluation of treatment engagement and recovery stages. Journal of Substance Abuse Treatment, 27(2), 89-97. doi:https://doi.org/10.1016/j.jsat.2004.03.001

Teesson, M., Marel, C., Darke, S., Ross, J., Slade, T., Burns, L., ... Mills, K. L. (2017). Trajectories of heroin use: 10-11-Year findings from the Australian Treatment Outcome Study. Addiction, 112(6), 1056-1068. doi:10.1111/add.13747

Tiger, R. (2013). Judging addicts: Drug courts and coercion in the justice system. NYU Press.

U.S. Department of Justice. (2002). I-ADAM in Eight Countries: Approaches and Challenges. Government Document. U.S. Department of Justice.

Voce, A., \& Sullivan, T. (2019). Drug use monitoring in Australia: Drug use among police detainees, 2018. Government Document. Australian Institute of Criminology.

Vuong, T., Ritter, A., Hughes, C., Shanahan, M., \& Barrett, L. (2019). Mandatory alcohol and drug treatment: What is it and does it work? DPMP Bulletin, (27).

Wagner, F. A., \& Anthony, J. C. (2002). From first drug use to drug dependence; developmental periods of risk for dependence upon marijuana, cocaine, and alcohol. Neuropsychopharmacology: official publication of the American College of Neuropsychopharmacology, 26(4), 479. doi:10.1016/S0893-133X(01)00367-0 
Werb, D., Kamarulzaman, A., Meacham, M. C., Rafful, C., Fischer, B., Strathdee, S. A., \& Wood, E. (2015). The effectiveness of compulsory drug treatment: A systematic review. International Journal of Drug Policy, 28, 1-9. doi:10.1016/j.drugpo. 2015.12.005

Wickersham, J. A., Azar, M. M., Cannon, C. M., Altice, F. L., \& Springer, S. A. (2015). Validation of a Brief Measure of Opioid Dependence: The Rapid Opioid Dependence Screen (RODS). Journal of correctional health care: the official Journal of the National Commission on Correctional Health Care, 21(1), 12-26. doi:10.1177/1078345814557513

Wood, E. F., Miller, M. K., \& Kaplan, T. (2017). Specialty Courts: Time for a Thorough Assessment. Miss. CL Rev. $36,332$.

Wundersitz, J. (2007). Criminal justice responses to drug and drug-related offending: are they working? Australian Institute of Criminology Canberra. 